\title{
$\beta$-Naphthoflavone protects mice from aristolochic acid-l-induced acute kidney injury in a CYP1A dependent mechanism
}

\author{
Ying XIAO ${ }^{1,2, \#}$, Xiang XUE ${ }^{1,2, \#}$, Yuan-feng WU ${ }^{1,2}$, Guo-zheng $\mathrm{XIN}^{1,2}$, Yong QIAN ${ }^{3}$, Tian-pei XIE ${ }^{3}$, Li-kun GONG ${ }^{1, *}$, Jin REN ${ }^{1, *}$ \\ ${ }^{1}$ Centre for Drug Safety and Evaluation Research, State Key Laboratory of New Drug Research, Shanghai Institute of Materia Medica, \\ Chinese Academy of Sciences, Shanghai 201203, China; ${ }^{2}$ Graduate School of the Chinese Academy of Sciences, Shanghai 201203, \\ China; ${ }^{3}$ Shanghai TenGen Biomedical Co Ltd, China
}

\begin{abstract}
Aim: The role of CYP1A in the protection of aristolochic acid (AA)l-induced nephrotoxicity has been suggested. In the present study we investigated the effects of $\beta$-naphthoflavone (BNF), a non-carcinogen CYP1A inducer, on AAl-induced kidney injury.

Methods: Mice were pretreated with $80 \mathrm{mg} / \mathrm{kg}$ BNF by daily intraperitoneal injection (ip) for 3 days followed by a single ip of $10 \mathrm{mg} / \mathrm{kg}$ AAI. AAI and its major metabolites in blood, liver and kidney, the expression of CYP1A1 and CYP1A2 in microsomes of liver and kidney, as well as the nephrotoxicity were evaluated.

Results: BNF pretreatment prevented AAI-induced renal damage by facilitating the disposal of AAI in liver. BNF pretreatment induced the expression of CYP1A1 in both liver and kidney; but the induction of CYP1A2 was only observed in liver.

Conclusion: BNF prevents AAl-induced kidney toxicity primarily through CYP1A induction.
\end{abstract}

Keywords: aristolochic acid; kidney injury; beta-naphthoflavone; biotransformation; CYP1A

Acta Pharmacologica Sinica (2009) 30: 1559-1565; doi: 10.1038/aps.2009.156

\section{Introduction}

Aristolochic acid (AA) is a mixture of structurally related nitrophenanthrene carboxylic acids and its major nephrotoxic constituent is 8-methoxy-6-nitro-phenanthro-(3,4-d)-1,3-dioxolo-5-carboxylic acid (aristolochic acid I, AAI) ${ }^{[1]}$. AA has been characterized as a carcinogen and nephrotoxin in many species including human, rabbit and rat $^{[2-4]}$. Since the first observation in Belgium in $1993^{[5]}$, more than 200 cases of AA-induced nephropathy (AAN) have been identified worldwide ${ }^{[6]}$. AA is also suspected as an etiologic factor for Balkan endemic nephropathy $(\mathrm{BEN})^{[7]}$, which shares many clinic and histological characteristics with $\mathrm{AAN}^{[8]}$ and affects at least 25000 inhabitants in certain rural areas of the Balkan ${ }^{[9]}$. However, there is no effective therapeutics for AAN due to the poor understanding of the mechanism of AA-induced kidney toxicity ${ }^{[10]}$.

Cytochrome P450 enzymes (CYP, P450) catalyze the metabolism of a wide variety of xenobiotics ${ }^{[11]}$. Among the P450 superfamily, CYP1A is known to be involved in activa-

\footnotetext{
\# These authors contributed equally to this work.

* To whom correspondence should be addressed.

E-mail Ikgong@mail.shcnc.ac.cn (Li-kun GONG) jren@mail.shcnc.ac.cn (Jin REN)

Received 2009-05-19 Accepted 2009-09-21
}

tion/detoxification of a variety of procarcinogens such as 3-methylcholanthrene $(3-\mathrm{MC})^{[12]}$. It has been reported that in hepatic microsomes, AA is metabolized to aristolochic acid Ia (AAIa) under aerobic conditions in vitro ${ }^{[13,14]}$. An in vivo study suggests that aristolactams (AL) are the major metabolites in kidney ${ }^{[15]}$. Our previous studies demonstrated that AAI-induced nephrotoxicity was more severe when the liver-specific NADPH-cytochrome P450 reductase (CPR) was deficient $^{[16]}$, and the induction of CYP1A significantly reduced AAI-induced kidney toxicity in wild-type mice ${ }^{[17]}$. Šístková et al have also demonstrated that human cytochromes P450 1A1 and $1 \mathrm{~A} 2$ are the most important enzymes in detoxicating AAI to $\mathrm{AAIa}^{[18]}$. These findings suggest that hepatic P450/CPR plays a role in detoxifying AAI to prevent the renal injury and CYP1A is the major enzyme involved in this process. However, the carcinogenicity of the known CYP1 inducer, 3-MC limits its potential use as a therapeutics and alternatives need to be explored ${ }^{[19]}$.

The $\beta$-naphthoflavone (BNF) is a synthetic derivative of a naturally occurring flavonoid. BNF itself is not toxic or carcinogenic and induces CYP1A expression through the activation of aryl hydrocarbon receptor ${ }^{[20-22]}$. We therefore investigated the effect of BNF on AAI-induced kidney toxicity. 


\section{Materials and methods Chemicals}

AAI was purchased from Sigma Chemical Co (St Louis, MO, USA) and BNF was from Merk \& Co (Merck Schuchardt OHG, Hohenbrunn, Germany). Aristolactam I (ALI) was a gift from Dr Ming-hua XU (Shanghai Institute of Materia Medica).

\section{Animal experiments}

Male C57BL/ 6 mice (6 weeks old, 18-22 g) were obtained from Shanghai Laboratory Animal Center. All animal experiments were approved by the Shanghai Animal Care and Use Committee [Certificate No.SCXK (Shanghai) 2002-0010]. Animals were divided into three groups $(n=15)$ for different treatments including AAI group (mice receiving corn oil (CO) via intraperitoneal injection (ip) daily for $3 \mathrm{~d}$ followed by a single ip of $10 \mathrm{mg} / \mathrm{kg}$ AAI prepared in saline) $24 \mathrm{~h}$ after the last injection of $\mathrm{CO}, \mathrm{BNF}+\mathrm{AAI}$ group (mice receiving $80 \mathrm{mg} / \mathrm{kg} \mathrm{BNF}$ prepared in $\mathrm{CO}$ daily via ip for $3 \mathrm{~d}$ followed by a single ip of $10 \mathrm{mg} / \mathrm{kg}$ AAI $24 \mathrm{~h}$ after the last injection of BNF) and control group (mice receiving $\mathrm{CO}$ ip daily for $3 \mathrm{~d}$ followed by a single ip of saline $24 \mathrm{~h}$ after the last injection of $\mathrm{CO}$ ). Serum biochemistry and histopathology were performed on d 3, 7, 14 after last injection. Serum urea nitrogen (BUN) and creatinine (CRE) were measured by an automatic HITACHI Clinical Analyzer Model 7080 (Hitachi High-Technologies Corporation, Tokyo, Japan). For the preparation of microsomes and mRNA from tissues, mice were treated with BNF or CO $(n=5)$ via ip daily for $3 \mathrm{~d}$ and tissues (liver and kidney) were harvested $24 \mathrm{~h}$ after the last injection.

\section{Histopathology}

Kidneys were collected at indicated time points and fixed in $10 \%$ formalin solution before being embedded in paraffin for sections ( $3 \mu \mathrm{m}$ thick). Sections were stained with hematoxylin and eosin (H\&E) by a standard pathology procedure ${ }^{[23]}$, and then evaluated by a pathologist. Immunostaining of a-SMA was performed by using the anti-mouse a-SMA antibody (1:800, Sigma, St Louis, MO, USA) and avidin-biotin-peroxidase complex $(\mathrm{ABC})$ method described previously ${ }^{[24]}$. The brownish-color was considered to be evidence of a positive expression of a-SMA in the interstitial cells. Stained vascular cells were considered as positive internal controls. For the morphometric evaluations, three random and nonoverlapping areas $\left(0.125 \mathrm{~mm}^{2}\right.$ per area) were chosen and the quantification of area of positively stained cells was carried out using Leica image analyzing software (Leica Qwin). In situ TUNEL assay (Roche Diagnostics, Indianapolis, IN, USA) was performed according to the supplier's instructions. Briefly, deparaffinized sections were labeled with TdT and biotinylated dUTP, and then were examined under a fluorescence microscope. Approximately, 3000 nuclei in five 200× fields were counted.

\section{Detection of AAI and its major metabolites in blood, liver and kidney}

For the determination of AAI concentrations, blood samples were collected by tail bleeding at various time points after a single ip of $10 \mathrm{mg} / \mathrm{kg}$ AAI. Blood samples ( $20 \mu \mathrm{L}$ each) were collected in heparin-coated capillaries and were mixed with an equal volume of saline. The samples were spun at $4000 \times g$ for $5 \mathrm{~min}$ at $4^{\circ} \mathrm{C}$. Tissue samples were homogenized in saline, the supernatant was removed and spun at $14000 \times g$ for $10 \mathrm{~min}$, and then the supernatants were mixed with one-half volume of methanol and spun again at $14000 \times g$ for 5 min to remove precipitated proteins. Aliquots of the final supernatants were analyzed and quantified for the levels of AAI and the metabolites AAIa and ALI by HPLC.

\section{HPLC analysis}

The quantification of AAI and its metabolites in the samples was performed on an HP1100 HPLC system (Agilent Technologies, Palo Alto, CA, USA). HPLC/UV analysis was carried out using a Welchrom ${ }^{\mathrm{TM}} \mathrm{XB}-\mathrm{C} 18$ column $(5 \mu \mathrm{m}, 4.6 \times 250$ $\mathrm{mm}$; Welch Materials, MD, USA) at a flow rate of $0.8 \mathrm{~mL} / \mathrm{min}$. An isocratic mobile phase of methanol: $0.1 \%$ acetic acid in $\mathrm{H}_{2} \mathrm{O}$ (7:3) was used for separation. The UV detector was set at 250 nm.

For AAI, the linear ranges of the calibration curves were $0.8-40 \mu \mathrm{g} / \mathrm{mL}$ in serum and $0.1-10 \mu \mathrm{g} / \mathrm{mL}$ in liver and kidney, the regression equation was $y=46478 x-15390\left(r^{2}=0.9964\right)$, $y=48044 x-1973.5\left(r^{2}=0.9985\right)$ and $y=47845 x-6422.8\left(r^{2}=0.9956\right)$, respectively, where $y$ is the peak area and $x$ is the concentration of analyte. The intra and inter-day precisions referred by relative standard deviation (RSD) were less than $5.35 \%$ and $12.43 \%$ for serum samples, less than $4.71 \%$ and $8.61 \%$ for liver samples, as well as less than $5.21 \%$ and $6.18 \%$ for kidney samples. The average percentage recoveries were no less than $70.88 \%, 84.53 \%$, and $90.01 \%$ for serum, liver and kidney samples, respectively.

For ALI, the linear ranges of the calibration curves were 0.1-10 $\mathrm{\mu g} / \mathrm{mL}$ in liver and kidney, the regression equation was $y=39991 x-936.4\left(r^{2}=0.9986\right)$ and $y=40231 x-6718.2\left(r^{2}=0.9919\right)$, respectively. The intra and inter-day precisions referred by relative standard deviation (RSD) were less than $7.84 \%$ and $14.89 \%$ for liver samples, as well as less than $5.07 \%$ and $12.32 \%$ for kidney samples. The average percentage recoveries were no less than $79.36 \%$ and $88.64 \%$ for liver and kidney samples, respectively.

In addition, LC-MS/MS analysis was conducted on an Agilent 6300 LC/MSD Trap XCT Ultra (Agilent Technologies Deutschland $\mathrm{GmbH}$, Waldbronn, Germany) to confirm and characterize AAI and its metabolites. The detect conditions refered to Xiao et $a l^{[16]}$.

\section{Real-time RT-PCR}

Total RNA was isolated by using UNIQ-10 column \& TRIZOL total RNA isolation kit (Sangon Biotech Co, Shanghai, China). One microgram of total RNA was used for reverse transcription in a reaction volume of $20 \mu \mathrm{L}$ using Cloned AMV Reverse Transcriptase (Invitrogen, Carlsbad, CA, USA). Two microliters of cDNA was used for real time PCR using TaKaRa Ex Taq R-PCR Version 2.1 kit (TaKaRa Biomedicals Inc, Shiga, Japan). Gene-specific PCR primers for CYP1A1, CYP1A2, 
CPR, and $\beta$-actin were listed in Table 1 and PCR signal was detected with a DNA Engine Opticon 2 Continuous Fluorescence Detection System (Bio-Rad Laboratories, Inc, CA, USA). PCR was monitored for 45 cycles with annealing temperature at $60{ }^{\circ} \mathrm{C}$. At the end of the PCR cycles, melting curve analysis and $2 \%$ agar electrophoresis was performed to assess the purity of the PCR products. Negative control reactions (no template) were routinely included to monitor potential contamination of reagents. Standard curves were generated for CYP1A1, CYP1A2, CPR, and $\beta$-actin, respectively. Relative amounts of CYP1A1, CYP1A2, and CPR mRNA were normalized to $\beta$-actin mRNA.

Table 1. Primers for real-time PCR.

\begin{tabular}{|c|c|c|c|}
\hline \multicolumn{2}{|c|}{ Primer } & \multirow{2}{*}{$\begin{array}{c}\text { Sequence }\left(5^{\prime}-3^{\prime}\right) \\
\text { GACCCTTACAAGTATTTGGTCGT }\end{array}$} & \multirow{2}{*}{$\begin{array}{r}\text { Product size } \\
145 \mathrm{bp}\end{array}$} \\
\hline CYP1A1 & Forward & & \\
\hline & Reverse & GGTATCCAGAGCCAGTAACCT & \\
\hline \multirow[t]{2}{*}{ CYP1A2 } & Forward & CCAGGTGGTGGAATCGGTG & 194 bp \\
\hline & Reverse & TCTTAAACCTCTTGAGGGCCG & \\
\hline \multirow[t]{2}{*}{ CPR } & Forward & ATGGGGGACTCTCACGAAGAC & $169 \mathrm{bp}$ \\
\hline & Reverse & TCTTGCTGAACTCCGGTATCTC & \\
\hline \multirow[t]{2}{*}{$\beta$-Actin } & Forward & GAGATTACTGCTCTGGCTCCTAG & $146 \mathrm{bp}$ \\
\hline & Reverse & TCATCGTACTCCTGCTTGCTG & \\
\hline
\end{tabular}

\section{Western blotting analysis}

The concentration of protein extracts from mouse hepatic or renal microsomes was determined using BCA kit (Pierce, Rockford, IL, USA) and $30 \mu \mathrm{g}$ protein lysates were separated on $10 \%$ SDA-PAGE followed by being transferred to nitrocellular membrane. Western-blotting analysis was performed as described $^{[25]}$ and the signal was detected using an ECL system (Amersham, Piscataway, NJ). Antibodies used in this study included monoclonal anti-mouse CYP1A1 (1:100; Santa Cruz, California, USA), sheep anti-rat CYP1A2 (1:1000; Chemicon, Temecula, CA, USA), and polyclonal rabbit anti-mouse cytochrome P450 reductase (1:1000; Abcam, Cambridge, UK) .

\section{Statistical analysis}

All Data are expressed as mean \pm SD. Statistical differences were determined by Student's $t$-test and one-way ANOVA followed by a Tukey post-hoc test. The criterion for statistical significance was $P<0.05$.

\section{Results}

\section{BNF protects mouse from AAl-induced renal damages}

The conventional renal function index, such as the serum BUN and CRE, increased markedly at day 7 and then decreased to normal level at day 14 in the AAI group. BNF pretreatment significantly reduced the AAI-induced increase of BUN and CRE with no difference compared to those in control group (Figure 1).

The progress of the lesions in kidney after AAI administration was observed by histopathological examinations.
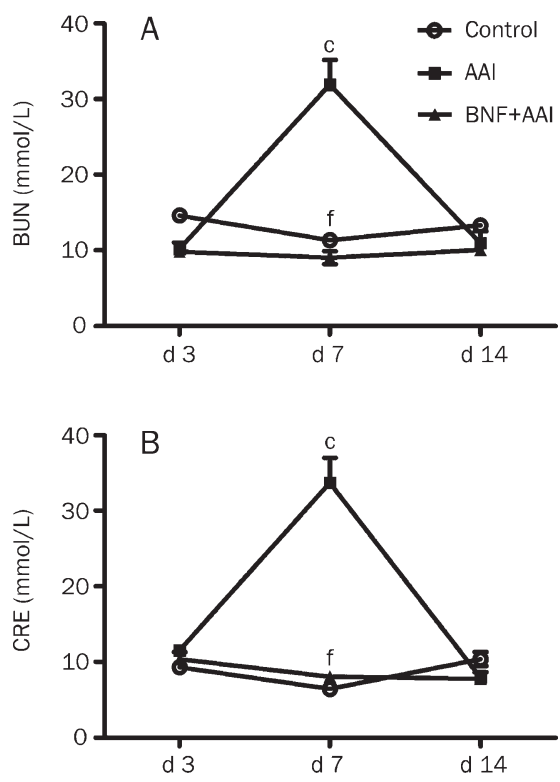

Figure 1. Effects of BNF on blood urea nitrogen (BUN) and serum creatinine (CRE) in AAl-treated mice. Mice were divided into three groups. The AAl group was treated with a single ip of $10 \mathrm{mg} / \mathrm{kg}$ AAl. The BNF+AAI group was given $80 \mathrm{mg} / \mathrm{kg}$ BNF daily for 3 days prior to the AAl injection. The control group was injected with vehicle solution. Mice were sacrificed at indicated time after AAl administration. Blood samples were collected to obtain serum for measurement of (A) BUN and (B) CRE. Data are expressed as mean \pm SD. $n=5 . \quad{ }^{c} P<0.01$ vs control group; ${ }^{f} P<0.01$ vs AAI group by ANOVA test.

Slight tubular dilation in kidney was seen after 3 days of AAI injection. Then, lesions of extensive tubular necrosis, tubular dilation and massive granular and hyaline cast occurred after 7 days of AAI administration. Lesions characterized by tubular dilation (atrophy) along with discrete tubular necrosis and slight interstitial fibrosis were seen in kidney after 14 days of AAI injection. Simultaneously, kidneys from mice of $\mathrm{BNF}+\mathrm{AAI}$ group displayed much less lesions (Figure 2).

Further analysis by using TUNEL assay indicated that the renal damage was associated with induction of apoptosis, an early event after AAI administration (Figure 3A and 3C). BNF pretreatment greatly inhibited AAI-induced apoptosis in tubular epithelium cells. In addition, immunohistochemistry analysis revealed that BNF prevented AAI-induced tubulointerstitial fibrosis by inhibiting AAI-induced a-SMA expression, a phenotypic marker of myofibroblasts (Figure 3B and 3D). Together, these results demonstrate that BNF protects mice against AAI-induced renal damage.

\section{AAI was rapidly metabolized in BNF pretreated mice.}

We next studied the pharmacokinetics of AAI and its metabolites in vivo. BNF pretreatment markedly decreased the exposure level of AAI in mice as indicated by much lower value of pharmacokinetic parameters such as $C_{\max }, t_{\max }$, and AUC of $\mathrm{AAI}$ in $\mathrm{BNF}+\mathrm{AAI}$ group than that in $\mathrm{AAI}$ group following a single ip of AAI at $10 \mathrm{mg} / \mathrm{kg}$ (Figure 4A, Table 2). Simulta- 

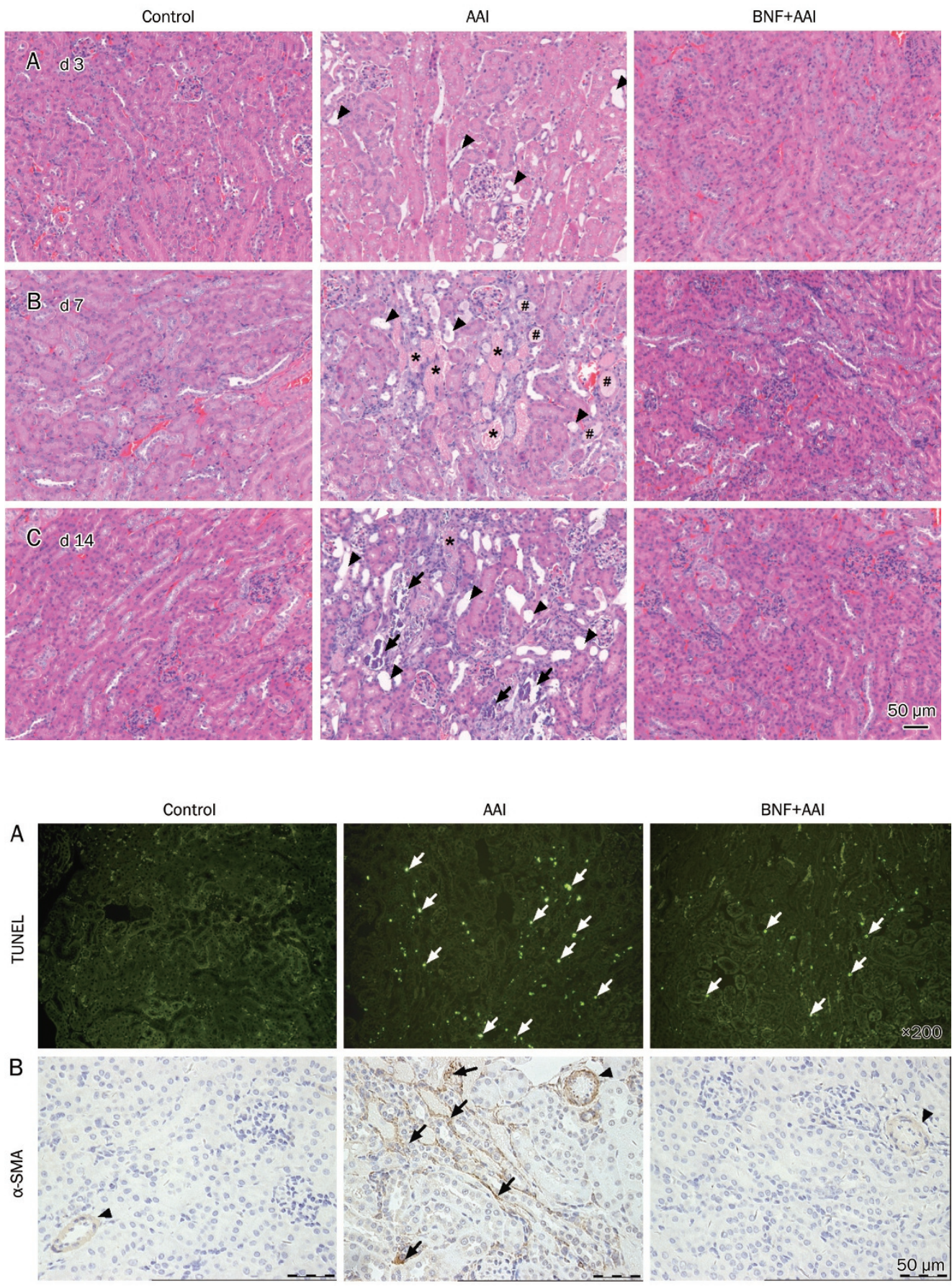

C
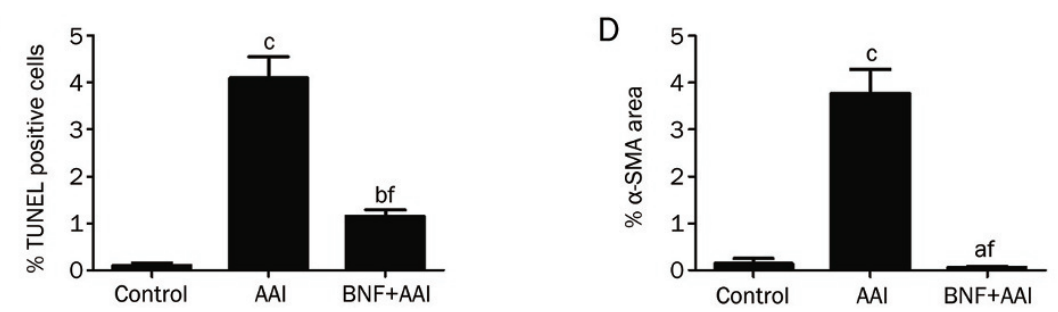

Figure 2. Kidney histological features of mice with AAl injection. Mice were sacrificed at indicated time after AAI administration. Kidneys were collected to perform H\&E staining on (A) day 3, (B) day 7 and (C) day 14. Arrowheads, tubular dilation; stars, tubular necrosis and granular cast; pound sign, hyaline cast; arrows, mineralization. Scale bar, $50 \mu \mathrm{m}$.

Figure 3. Immunohistochemical staining of kidney from AAl-treated mice. (A) In situ TUNEL staining after 3 days of AAl injection. Green fluorescences (arrows) were observed as positive staining of apoptotic cells. Magnification, $\times 200$. (B) Immunostaining of $\alpha$-SMA after 7 days of AAI injection. Expression of $\alpha$-SMA in tubulointerstitium (arrows) was indicated, and staining on vessels (arrowheads) was shown as an internal positive control, scale bar, $50 \mu \mathrm{m}$. (C) Scoring of apoptotic cells. (D) Scoring of expression of $\alpha$-SMA. Data are expressed as mean \pm SD. $n=5 .{ }^{\mathrm{a}} P>0.05,{ }^{\mathrm{b}} P<0.05$, ${ }^{\mathrm{c}} P<0.01$ vs control group; ${ }^{\mathrm{f}} P<0.01$ vs AAI group by ANOVA test. neously, the level of AAIa, the major metabolite of AAI, was higher in mice in the BNF+AAI group than that in AAI group
(Figure 4B). These results suggest that BNF-pretreatment can enhance the metabolism of AAI in vivo. 

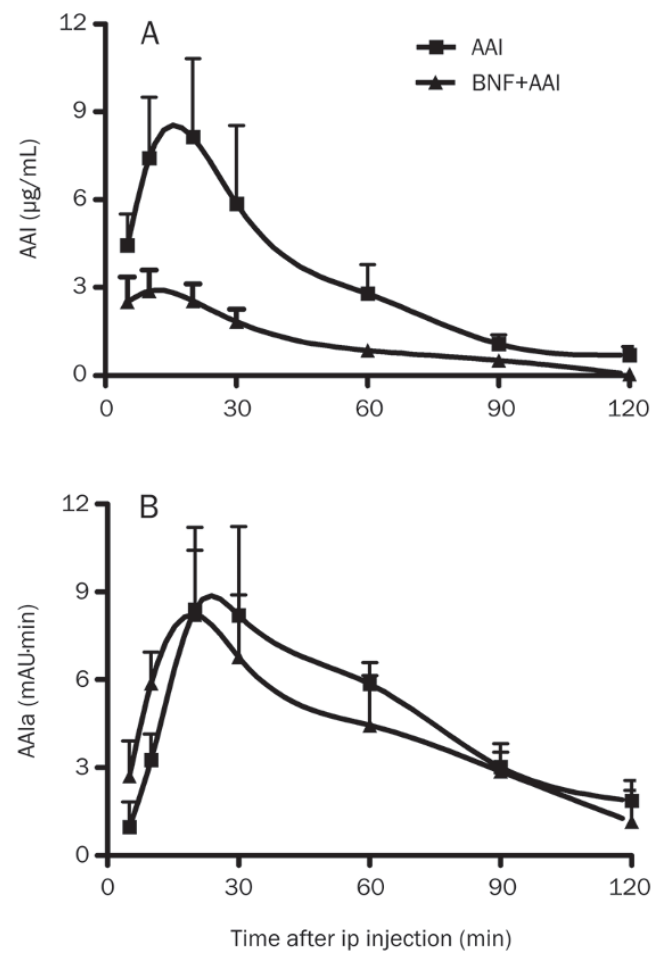

Figure 4. Levels of AAl and its major metabolite AAla in serum. Blood samples were collected from mice of AAI and BNF+AAl group at indicated time points after AAl injection. Serum levels of AAI were measured and data are expressed as mean \pm SD. $n=5$.

Table 2. Comparison of pharmacokinetic parameters between mice in AAl group and that in BNF+AAl group. $n=5$. Values are expressed as mean \pm SD. ${ }^{b} P<0.05,{ }^{c} P<0.01$ vs AAl group.

\begin{tabular}{llccc}
\hline Groups & $C_{\max }(\mu \mathrm{g} / \mathrm{mL})$ & $t_{\max }(\min )$ & AUC $(\mathrm{min} \cdot \mu \mathrm{g} / \mathrm{mL})$ & $t_{1 / 2}(\min )$ \\
\hline AAl & $8.73 \pm 1.57$ & $16.00 \pm 5.48$ & $418.37 \pm 126.09$ & $27.55 \pm 3.37$ \\
AAl+BNF & $3.08 \pm 0.61^{\mathrm{C}}$ & $6.25 \pm 2.50^{\mathrm{b}}$ & $149.84 \pm 20.30^{\mathrm{b}}$ & $31.46 \pm 8.80$ \\
\hline
\end{tabular}

\section{BNF reduced the accumulation of AAI in kidney}

To examine whether the change in pharmacokinetics of AAI upon BNF pretreatment was due to the change in the tissue distribution of AAI, AAI and its major metabolites in liver and kidney was measured by HPLC (Figure 5). Thirty minutes after a single ip of AAI at $10 \mathrm{mg} / \mathrm{kg}$, the level of AAI in kidney was about 3-fold higher than that in liver and BNF pretreatment resulted in a 3-fold reduction in the level of AAI in both liver and kidney (Figure 5A). The level of AAIa was higher in liver than that in kidney and was not significantly affected by BNF pretreatment (Figure 5B). Another metabolite, ALI, was about 4-fold higher in kidney than that in liver and BNF pretreatment decreased ALI formation in both liver and kidney (Figure 5C). Together, these results suggest that BNF pretreatment decreases the accumulation of AAI in kidney of mice.
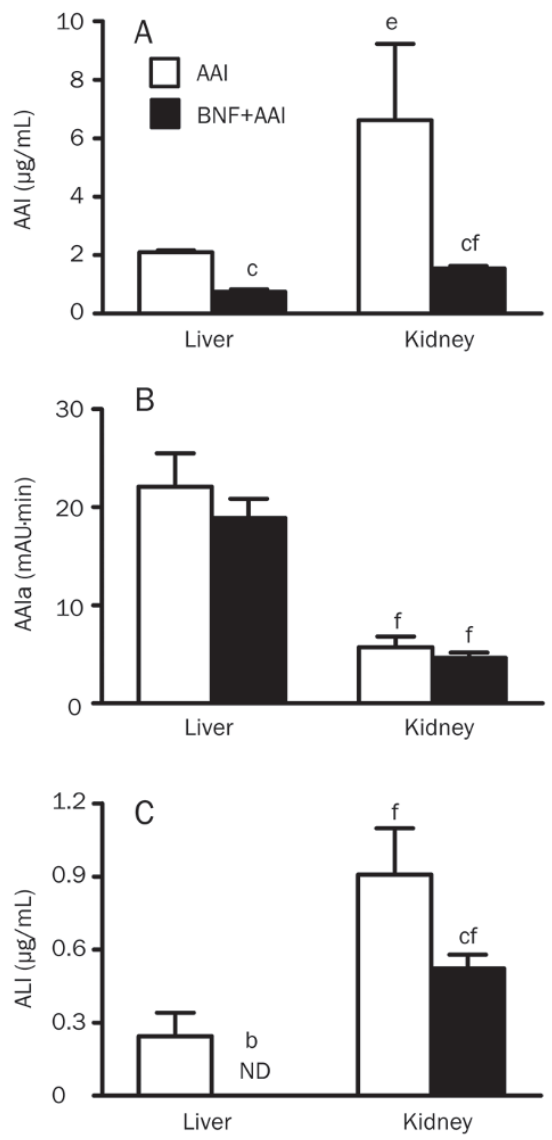

Figure 5. AAI and its major metabolites AAla and ALI in liver and kidney. Tissue samples from mice of AAl and BNF+AAl group were collected at 30 minutes after AAl injection to determine the levels of AAl and AAla. (A) AAI, (B) AAla, (C) ALI. $n=5$. Data are expressed as mean $\pm S D$. ND, not detectable. ${ }^{\mathrm{b}} P<0.05,{ }^{\mathrm{c}} P<0.01$ vs AAl group. ${ }^{\mathrm{e}} P<0.05,{ }^{\mathrm{f}} P<0.01$ vs the level of AAl in liver.

The expressions of CYP1A1 and CYP1A2 were different in liver from that in kidney from BNF-pretreated mice

To investigate the discrepancy of liver and kidney in metabolizing AAI, we then examined if BNF regulated the expression of CYP1A1 and CYP1A2 differentially in mice. After BNF treatment, the mRNA levels of CYP1A1, CYP1A2, and CPR in liver was increased about 4-fold, 16-fold, and 3-fold, respectively, compared to vehicle-treated group. However, in kidney, only CYP1A1 mRNA levels showed a 2-fold increase after BNF treatment (Figure 6A, 6B and 6C). Similarly, Western-blotting analysis revealed that protein levels of CYP1A1, CYP1A2 and CPR in liver was greatly upregulated after BNF treatment, but only CYP1A1 protein was induced in kidney (Figure 6D). These results suggest that BNF induces the expressions of both CYP1A1 and CYP1A2 in liver, but only CYP1A1 in kidney.

\section{Discussion}

AAN is a unique disease characterized by prominent tubu- 

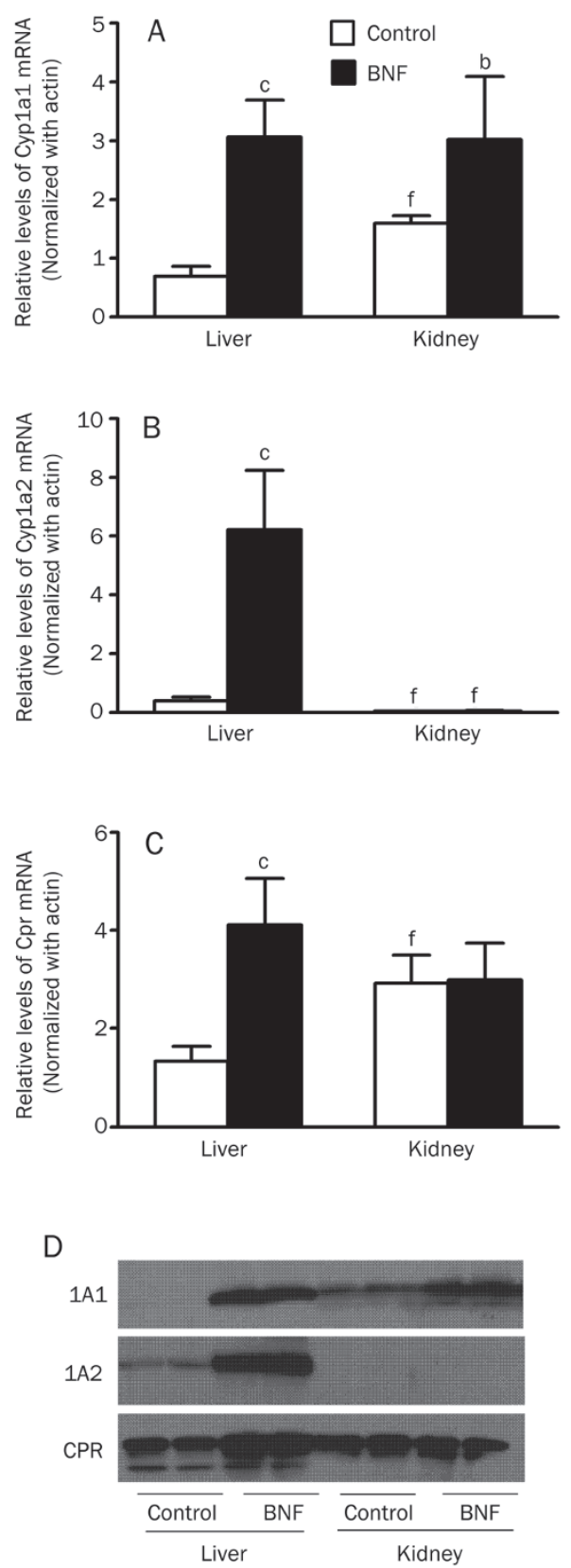

Figure 6. CYP1A1, CYP1A2, and CPR mRNA and protein levels in liver and kidney. Tissues were collected at $24 \mathrm{~h}$ after the last injection from mice of $\mathrm{CO}$ and BNF group. Microsomes were prepared and RNA was extracted. (A) CYP1A1, (B) CYP1A2 and (C) CPR mRNA by real-time PCR analysis are shown. $n=5$. Data are expressed as mean \pm SD. ${ }^{b} P<0.05,{ }^{\circ} P<0.01$ vs control group. ${ }^{f} P<0.01$ vs the level of mRNA in liver. (D) Western blotting analysis of CYP1A1, CYP1A2, and CPR proteins.

lar atrophy and interstitial fibrosis ${ }^{[26,27]}$. Up to now, therapeutic strategies have been mainly conservative when renal insufficiency is detected ${ }^{[10]}$. Angiotensin-converting enzyme inhibitors did not modify the evolution of the renal disease ${ }^{[28]}$. Previous studies have investigated possible mechanisms of AA-induced nephrotoxicity both in vitro and in vivo and have suggested the role of AAI-induced apoptosis in renal tubular cells through either the endoplasmic reticulum (ER) stress pathway or the mitochondrial cell death pathway ${ }^{[29,30]}$. In this study, BNF pretreatment prevented the tubular apoptosis, tubular necrosis and tubulointerstitial fibrosis, along with improved renal function by increasing the metabolism of AAI so as to decrease its accumulation in kidney. Our results also suggest that CYP1A enzyme is critical during this process.

AAIa and ALI were the major metabolites of AAI formed in liver and in kidney, respectively. After BNF treatment, both AAI and ALI were decreased, but AAIa was unchanged in either liver or kidney, compared to the vehicle-treated mice. The lack of increase in AAIa raises the possibility that AAIa might have undergone an extensively phase II conjugation and was readily eliminated from the body ${ }^{[31]}$. Furthermore, considering AAIa was much less cytotoxic and mutagenic than $\mathrm{AAI}^{[14,32]}$, we speculate that the formation of AAIa by CYP1A plays a role in detoxicification of AAI in vivo in contrast to its toxicity in vitro. The discrepant roles of CYP1A in vivo and in vitro have been shown before ${ }^{[33-35]}$ and our study supports that CYP1A is cytoprotective rather than cytotoxic in vivo ${ }^{[36]}$.

In summary, BNF can increase the metabolism of AAI to AAIa by inducing CYP1A to decrease the accumulation of AAI in kidney, and subsequently protect AAI-induced nephrotoxicity.

\section{Acknowledgments}

We thank Prof Yi-zheng WANG for reading the manuscript, Prof Xiao-yan CHEN and Prof Da-fang ZHONG for providing the LC-MS/MS system, Yu-Ya WANG, Hua SHENG, Hen-Lei LU, Jin LU for technical assistance. This work was supported by National Grand Fundamental Research 973 Program of China (№ 2006CB504700) and Key projects of National Science and Technology Pillar Program (2008ZX09305-007 and 2009ZX09501-033)

\section{Author contribution}

Ying XIAO, Xiang XUE, Li-kun GONG, and Jin REN designed the experiment; Xiang XUE, Ying XIAO, Yuan-feng WU and Guo-zhen XIN performed research; Yong QIAN and Tian-pei XIE contributed new analytical tools and reagents; Xiang XUE and Ying XIAO analyzed data; Xiang XUE and Ying XIAO wrote the manuscript. Li-kun GONG and Jin REN revised the manuscript.

\section{References}

1 Shibutani S, Dong H, Suzuki N, Ueda S, Miller F, Grollman AP. Selective toxicity of aristolochic acids I and II. Drug Metab Dispos 2007; 35: 1217-22.

2 Nortier JL, Martinez MC, Schmeiser HH, Arlt VM, Bieler CA, Petein M, et al. Urothelial carcinoma associated with the use of a Chinese herb (Aristolochia fangchi). N Engl J Med 2000; 342: 1686-92.

3 Cosyns JP, Dehoux JP, Guiot Y, Goebbels RM, Robert A, Bernard AM, et al. Chronic aristolochic acid toxicity in rabbits: a model of Chinese herbs nephropathy? Kidney Int 2001; 59: 2164-73.

4 Debelle FD, Nortier JL, De Prez EG, Garbar CH, Vienne AR, Salmon IJ, et al. Aristolochic acids induce chronic renal failure with interstitial fibrosis in salt-depleted rats. J Am Soc Nephrol 2002; 13: 431-6. 
5 Vanherweghem JL, Depierreux M, Tielemans C, Abramowicz D, Dratwa $\mathrm{M}$, Jadoul $\mathrm{M}$, et al. Rapidly progressive interstitial renal fibrosis in young women: association with slimming regimen including Chinese herbs. Lancet 1993; 341 (8842): 387-91.

6 Stiborova M, Frei E, Arlt VM, Schmeiser HH. Metabolic activation of carcinogenic aristolochic acid, a risk factor for Balkan endemic nephropathy. Mutation Res 2008; 658: 55-67.

7 Grollman AP, Shibutani S, Moriya M, Miller F, Wu L, Moll U, et al. Aristolochic acid and the etiology of endemic (Balkan) nephropathy. Proc Natl Acad Sci USA 2007; 104: 12129-34.

8 de Jonge $\mathrm{H}$, Vanrenterghem $\mathrm{Y}$. Aristolochic acid: the common culprit of Chinese herbs nephropathy and Balkan endemic nephropathy. Nephrol Dial Transplant 2008; 23: 39-41.

9 Arlt VM, Stiborova M, vom Brocke J, Simoes ML, Lord GM, Nortier JL, et al. Aristolochic acid mutagenesis: molecular clues to the aetiology of Balkan endemic nephropathy-associated urothelial cancer. Carcinogenesis 2007; 28: 2253-61.

10 Nortier JL, Vanherweghem JL. For patients taking herbal therapy-lessons from aristolochic acid nephropathy. Nephrol Dial Transplant 2007; 22: 1512-7.

11 Nelson DR, Koymans L, Kamataki T, Stegeman JJ, Feyereisen R, Waxman DJ, et al. P450 superfamily: Update on new sequences, gene mapping, accession numbers and nomenclature. Pharmacogenetics 1996; 6: 1-42.

12 Moorthy B, Muthiah K, Fazili IS, Kondraganti SR, Wang L, Couroucli $\mathrm{XI}$, et al. 3-Methylcholanthrene elicits DNA adduct formation in the CYP1A1 promoter region and attenuates reporter gene expression in rat H4IIE cells. Biochem Biophys Res Commun 2007; 354: 1071-7.

13 Stiborova M, Frei E, Hodek P, Wiessler M, Schmeiser HH. Human hepatic and renal microsomes, cytochromes P450 1A1/2, NADPH: cytochrome $\mathrm{P} 450$ reductase and prostaglandin $\mathrm{H}$ synthase mediate the formation of aristolochic acid-DNA adducts found in patients with urothelial cancer. Int J Cancer 2005; 113: 189-97.

14 Schmeiser HH, Pool BL, Wiessler M. Identification and mutagenicity of metabolites of aristolochic acid formed by rat liver. Carcinogenesis 1986; 7: 59-63.

15 Krumbiegel G, Hallensleben J, Mennicke WH, Rittmann N, Roth HJ. Studies on the metabolism of aristolochic acids I and II. Xenobiotica 1987; 17: 981-91.

16 Xiao Y, Ge M, Xue X, Wang C, Wang H, Wu X, et al. Hepatic cytochrome P450s metabolize aristolochic acid and reduce its kidney toxicity. Kidney Int 2008; 73: 1231-9.

17 Xue X, Xiao Y, Zhu H, Wang H, Liu Y, Xie T, et al. Induction of P450 $1 \mathrm{~A}$ by 3-methylcholanthrene protects mice from aristolochic acid-Iinduced acute renal injury. Nephrol Dial Transplant 2008; 23: 307481.

18 Sistkova J, Hudecek J, Hodek P, Frei E, Schmeiser HH, Stiborova M. Human cytochromes P450 1A1 and 1A2 participate in detoxication of carcinogenic aristolochic acid. Neuro Endocrinol Lett 2008; 29: 733-7.

19 Rastogi S, Shukla Y, Paul BN, Chowdhuri DK, Khanna SK, Das M. Protective effect of Ocimum sanctum on 3-methylcholanthrene, 7,12-dimethylbenz(a)anthracene and aflatoxin B1 induced skin tumorigenesis in mice. Toxicol Appl Pharmacol 2007; 224: 228-40.

20 Brown JP, Dietrich PS. Mutagenicity of plant flavonols in the Salmonella/mammalian microsome test: activation of flavonol glycosides by mixed glycosidases from rat cecal bacteria and other sources. Mutat Res 1979; 66: 223-40.

21 Buening MK, Fortner JG, Kappas A, Corney AH. 7,8-Benzoflavone stimulates the metabolic activation of aflatoxin B1 to mutagens by human liver. Biochem Biophys Res Commun 1978; 82: 348-55.

22 Prochaska HJ, Talalay P. Regulatory mechanisms of monofunctional and bifunctional anticarcinogenic enzyme inducers in murine liver. Cancer Res 1988; 48: 4776-82.

23 Gu J, Cui H, Behr M, Zhang L, Zhang QY, Yang W, et al. In vivo mechanisms of tissue-selective drug toxicity: effects of liverspecific knockout of the NADPH-cytochrome P450 reductase gene on acetaminophen toxicity in kidney, lung, and nasal mucosa. Mol Pharmacol 2005; 67: 623-30.

24 Hsu SM, Raine L, Fanger H. Use of avidin-biotin-peroxidase complex $(A B C)$ in immunoperoxidase techniques: a comparison between $A B C$ and unlabeled antibody (PAP) procedures. J Histochem Cytochem 1981; 29: 577-80.

25 Cai Y, Qi XM, Gong LK, Liu LL, Chen FP, Xiao Y, et al. Tetrandrineinduced apoptosis in rat primary hepatocytes is initiated from mitochondria: caspases and endonuclease G (Endo G) pathway. Toxicology 2006; 218: 1-12.

26 Cosyns JP. Aristolochic acid and 'Chinese herbs nephropathy': a review of the evidence to date. Drug Saf 2003; 26: 33-48.

27 Yang L, Li X, Wang $\mathrm{H}$. Possible mechanisms explaining the tendency towards interstitial fibrosis in aristolochic acid-induced acute tubular necrosis. Nephrol Dial Transplant 2007; 22: 445-56.

28 Debelle FD, Nortier JL, Husson CP, De Prez EG, Vienne AR, Rombaut K, et al. The renin-angiotensin system blockade does not prevent renal interstitial fibrosis induced by aristolochic acids. Kidney Int 2004; 66 : 1815-25.

29 Hsin YH, Cheng CH, Tzen JT, Wu MJ, Shu KH, Chen HC. Effect of aristolochic acid on intracellular calcium concentration and its links with apoptosis in renal tubular cells. Apoptosis 2006; 11: 2167-77.

30 Qi X, Cai Y, Gong L, Liu L, Chen F, Xiao Y, et al. Role of mitochondrial permeability transition in human renal tubular epithelial cell death induced by aristolochic acid. Toxicol Appl Pharmacol 2007; 222: 105-10.

31 Chan W, Luo HB, Zheng Y, Cheng YK, Cai Z. Investigation of the metabolism and reductive activation of carcinogenic aristolochic acids in rats. Drug Metab Dispos 2007; 35: 866-74.

32 Balachandran P, Wei F, Lin RC, Khan IA, Pasco DS. Structure activity relationships of aristolochic acid analogues: toxicity in cultured renal epithelial cells. Kidney Int 2005; 67: 1797-805.

33 Stiborova M, Frei E, Wiessler M, Schmeiser HH. Human enzymes involved in the metabolic activation of carcinogenic aristolochic acids: evidence for reductive activation by cytochromes P450 1A1 and $1 \mathrm{~A} 2$. Chem Res Toxicol 2001; 14: 1128-37.

34 Uno S, Dalton TP, Derkenne S, Curran CP, Miller ML, Shertzer HG, et al. Oral exposure to benzo[a]pyrene in the mouse: detoxication by inducible cytochrome P450 is more important than metabolic activation. Mol Pharmacol 2004; 65: 1225-37.

35 Nebert DW, Dalton TP, Okey AB, Gonzalez FJ. Role of aryl hydrocarbon receptor-mediated induction of the CYP1 enzymes in environmental toxicity and cancer. J Biol Chem 2004; 279: 23847-50.

36 Nebert DW, Dalton TP. The role of cytochrome P450 enzymes in endogenous signalling pathways and environmental carcinogenesis. Nat Rev Cancer 2006; 6: 947-60. 